\section{THE IMPORTANCE OF LIPID PROFILE IN SECONDARY PREVENTION IN NSTEMI AND TROPININ NEGATIVE ACS}

${ }^{1}$ Sharaf Sheik-Ali*, ${ }^{2}$ Kula Ranjan, ${ }^{3}$ Svitlana Okoro. ${ }^{1}$ Barts and the London; ${ }^{2}$ Newham University Hospital, Consultant Cardiologist; ${ }^{3}$ Newham University Hospital; *Presenting Author

\subsection{6/heartjnl-2016-309890.86}

Brief Introduction The importance of conducting lipid profiles on admission is highlighted by NICE (National Institute of Clinical Excellence). There is specific guidance on the handling of lipid profiles of NSTEMI (non S-T elevation Myocardial infarction) and Tropinin negative ACS (acute coronary syndrome) patients (CG181). Within a busy East London district general hospital, we examined how effectively this was being undertaken.

Explanation of basic Methods We conducted a retrospective study of 90 patients; NSTEMI/ Tropinin negative ACS admitted between July 2014 and May 2015. (Age: 44-97 mean: 70.5). 77\% of patients had commodities which included diabetes, hypertension or a previous history of hypercholesterolemia. We extracted key data from individual patient notes, contacted General Practices and searched the database of patients available at Newham university hospital. This included lipid profiles; whether they were done on admission, the cholesterol level and whether a 3 month lipid profile was done before or after admission. We also recorded the statin type patients were commenced on or changed to. Each individual case was compared to the NICE guidelines on lipid handling in secondary prevention in NSTEMI and tropinin negative ACS patients.

Results Overall 67\% of patients (age: 44-97 mean: 70.5) who, according to the guidelines, should have had a lipid profile check on admission had not. $80 \%$ did not have their lipid profile checked after 3 months. Of those that did have a lipid profile on admission, $40 \%$ had a cholesterol level $>4.68 \%$ patients already on a statin were switched to atorvastatin $80 \mathrm{mg}$ as in accordance to the NICE guidelines. Of those known, $72 \%$ were started on a statin. Of those $72 \%, 85 \%$ were commenced on artorvastatin $80 \mathrm{mg}$.

Conclusions/Implications This shows that although we are good at putting patients admitted with NSTEMI/Tropinin negative ACS on atorvastatin $80 \mathrm{mg}$ (as in accordance to the NICE guidelines), we do not take into consideration their current lipid level on admission nor do we consider their 3 month post admission lipid profile. This situation makes it impossible to calculate whether the target of a fall of $40 \%$ in non-HDL cholesterol is reached after 3 months on statin therapy and significantly limits our knowledge on the patients condition. Moreover, $77 \%$ of the examined patients had comorbidities such as diabetes or hypertension and of these only $45 \%$ had a 3 month follow up lipid profile. This collectively demonstrates a lack of understanding of the importance of conducting a lipid profile on admission or 3 months after admission although clearly stated in the NICE guidelines.

\section{RESIDUAL ISCHAEMIA POST ACUTE CORONARY SYNDROME (ACS) -- DOES REVASCULARISATION IMPROVE PROGNOSIS?}

${ }^{1}$ Neha Sekhri, ${ }^{1}$ Kenneth Fung* ${ }^{2}$ Mohammed H Iqbal, ${ }^{2}$ Mohammed 0 Anwar, ${ }^{1}$ Daniel A Jones, ${ }^{1}$ Anthony Mathur, ${ }^{1}$ Andrew Wragg, ${ }^{1}$ Adam Timmis. ${ }^{1}$ Barts Heart Centre; ${ }^{2}$ Barts and the London School of Medicine and Dentistry; ${ }^{*}$ Presenting Author
Background Residual myocardial ischaemia early after acute coronary syndromes (ACS) is commonly regarded as an adverse prognostic sign and an indication for revascularisation.

However, the benefits of revascularisation for improving prognosis are not known.

Methods Analysis of 597 consecutive patients with ACS treated with coronary stenting, all of whom underwent adenosine stress cardiac magnetic resonance (CMR) perfusion imaging to guide revascularisation decisions. Follow-up data were obtained from hospital electronic health records.

Results The 597 patients (age $59 \pm 12$ years, 20\% female) underwent stress CMR scan, at median of 93 days (IQR: 41, 224 days) after coronary stenting with follow-up for 1.4 years (IQR: 0.6-2.7). Inducible perfusion defects were identified in $293(49 \%)$ patients of whom $18(6 \%)$ died during follow-up compared with $6(2.0 \%)$ patients with no perfusion defects $(\mathrm{p}=0.01)$.

Of the 293 patients with perfusion defects (Table 1), 70 (24\%) were revascularised (PCI 54, CABG 26) of whom 5 (7\%) died during follow-up compared with 13 (6\%) who were not evascularised $(p=0.66)$. K-M survival analysis confirmed that revascularisation was unassociated with survival benefit, regardless of the severity of ischaemia (Figure 1).

Conclusion In our patients with ACS and coronary stenting, inducible ischaemia was associated with increased risk of death during follow-up. Revascularisation did not appear to reduce the risk and should be reserved for improving symptoms in patients on optimal medical therapy.

\section{ROUTINE POST-OPERATIVE TROPONIN SCREENING FOR MYOCARDIAL INJURY AFTER NONCARDIAC SURGERY (MINS) EVENTS - A SINGLE CENTRE EXPERIENCE}

Matthew Jackson*, Nicola Cunningham, Mark Hammond, David Austin, Neil Swanson Mark de Belder, Michael Stewart. James Cook University Hospital; *Presenting Author

\subsection{6/heartjnl-2016-309890.88}

Introduction The VISION study demonstrated an association between 30-day mortality after surgery and raised post-operative troponin levels. ${ }^{1}$ Subsequently, diagnostic criteria for 'ischaemic' MINS were established excluding non-ischaemic aetiology. ${ }^{2}$ We evaluated our initial experiences with post-operative troponin monitoring, to look in-depth at patients who suffer MINS events.

Abstract 87 Table 1 Baseline characteristics in patients with perfusion defects $(n=293)$ stratified by revascularisation

\begin{tabular}{|c|c|c|c|}
\hline Variables & $\begin{array}{l}\text { No revascularisation ( } \mathrm{n} \\
=224 \text { ) }\end{array}$ & $\begin{array}{l}\text { Revascularisation ( } \mathrm{n} \\
=69)\end{array}$ & $\begin{array}{l}\mathrm{P} \\
\text { value }\end{array}$ \\
\hline Median age in years (IQR) & $61(53,71)$ & $56(49,67)$ & 0.05 \\
\hline Female & $53(24 \%)$ & $18(26 \%)$ & 0.68 \\
\hline Current smoker & $62(28 \%)$ & $26(38 \%)$ & 0.11 \\
\hline Diabetes & $69(31 \%)$ & $14(20 \%)$ & 0.09 \\
\hline $\begin{array}{l}\text { Median days from ACS to } \\
\text { CMR (IQR) }\end{array}$ & $103(42,286)$ & $54(34,171)$ & 0.03 \\
\hline Mild perfusion defect & $100(45 \%)$ & $19(27 \%)$ & 0.002 \\
\hline Moderate perfusion defect & $80(36 \%)$ & $23(33 \%)$ & \\
\hline Severe perfusion defect & $44(20 \%)$ & $27(39 \%)$ & \\
\hline Mortality & $13(6 \%)$ & $5(7 \%)$ & 0.66 \\
\hline
\end{tabular}

